\title{
Comparative Analysis of the Intrastromal MyoRing Implantation performed with the Femtosecond Laser
}

\author{
${ }^{1}$ Maksim V Sinitsyn, ${ }^{2}$ Nadezhda A Pozdeyeva, ${ }^{3}$ Nikolai P Pashtayev
}

\begin{abstract}
Purpose: To comparatively analyze the intrastromal MyoRing implantation with femtosecond laser (FL) using the standard and optimized technologies in the experiment and based on the long-term clinical-functional results of the patients with keratoconus (KC) at stages II and III.
\end{abstract}

Materials and methods: The experimental work was performed on 24 eyes of rabbits. All eyes were divided into six groups according to the method of operation. In the clinical part of the research, the surgical treatment of 70 patients (76 eyes) with $\mathrm{KC}$ at stages II and III was done. Depending on the technology of the operation, all patients were divided into two groups. Group I consisted of 29 patients (32 eyes) with KC, in which MyoRing implantation was performed according to the standard, group II consisted of 31 patients (32 eyes) with KC, in which MyoRing implantation was performed according to the optimized technology.

Results: Higher voltage was required for stretching samples of the second group in comparison with the third and the sixth group in comparison with the fifth group. In group I, during the period of 6 to 36 months the surgery reverses keratometry, corneal thickness above the MyoRing, and posterior corneal elevation. In group II, 12 months after surgery the clinical and functional parameters remained stable throughout the period of observation.

Conclusion: Greater reduction in corneal biomechanical stability was observed after formation of the intrastromal pocket in comparison with an intrastromal tunnel; a more pronounced increase in the strength characteristics of the cornea was observed after implantation of the ring in intrastromal pocket, compared with implantation intracorneal segments in intrastromal tunnel, and with increasing depth of intrastromal ring implantation. Application of optimized MyoRing implantation technology compared with standard allows more biomechanical parameters of the cornea to improve and reduce the risk of the ring protrusion.

Keywords: Femtosecond laser, Intracorneal segment, Keratoconus, MyoRing.

\footnotetext{
${ }^{1}$ Ophthalmologist, ${ }^{2}$ Professor and Deputy Director, ${ }^{3}$ Professor and Clinic Director

${ }^{1}$ Department of Ambulatory Surgery, The Cheboksary Branch of the S. Fyodorov Eye Microsurgery Federal State Institution Cheboksary, Russian Federation

${ }^{2,3}$ The Cheboksary Branch of the S. Fyodorov Eye Microsurgery Federal State Institution, Cheboksary, Russian Federation

Corresponding Author: Maksim V Sinitsyn, Ophthalmologist Department of Ambulatory Surgery, The Cheboksary Branch of the S. Fyodorov Eye Microsurgery Federal State Institution Cheboksary, Russian Federation, Phone: +88352369118 e-mail: mntksinicin@mail.ru
}

How to cite this article: Sinitsyn MV, Pozdeyeva NA, Pashtayev NP. Comparative Analysis of the Intrastromal MyoRing Implantation performed with the Femtosecond Laser. Int J Kerat Ect Cor Dis 2017;6(2):49-57.

\section{Source of support: Nil}

Conflict of interest: None

\section{INTRODUCTION}

Keratoconus is a genetic dystrophic corneal disease characterized by the disorder of cornea's biomechanic stability because of structural collagen fibers' disorganization which leads to the optical inhomogeneity of corneal tissue with its follow-up thinning, conical protrusion, and disorder of transparency. ${ }^{1,2}$ Recently, the intrastromal MyoRing implantation has gained a keen interest as it increases the biomechanic properties of a weakened cornea by means of a mechanical frame creation and also by a single-step correction of accompanying ametropia due to improvement of the sphericity and the applanation of the corneal surface. ${ }^{3,4}$ Daxer, who proposed this method for the first time, recommends implanting the MyoRing into the intrastromal pocket with a diameter of $9.0 \mathrm{~mm}$ formed at the depth of $300 \mu \mathrm{m}$, which does not take into account the individual corneal thickness. ${ }^{5,6}$ In literature, there are no data about the possibility of changing the intrastromal pocket's parameters (depth and diameter) and about the influence of this change on the corneal biomechanic parameters. There are no experimentations for studying the changes of corneal strength characteristics after intrastromal pockets' formation using the FL on different depths with and without the MyoRing implantation and this causes the present research.

\section{PURPOSE}

Comparative analysis of intrastromal MyoRing implantation with the FL using the standard and optimized technologies in the experiment and based on the longterm clinicali-functional results of the patients with KC at stages II and III.

\section{MATERIALS AND METHODS}

The corneas of isolated eyes of Chinchilla rabbits (mean 2-3 kg) were taken in the experimental part of the 


\begin{tabular}{|c|c|c|c|c|c|c|c|c|c|c|}
\hline \multirow[b]{2}{*}{ Groups } & \multirow[b]{2}{*}{$\begin{array}{l}\text { Technology of } \\
\text { operation }\end{array}$} & \multirow[b]{2}{*}{$\begin{array}{l}\text { Quantity of } \\
\text { examined } \\
\text { eyes }\end{array}$} & \multicolumn{2}{|c|}{$\begin{array}{c}\text { Parameters of } \\
\text { intrastromal pocket }\end{array}$} & \multicolumn{3}{|c|}{$\begin{array}{c}\text { Parameters of } \\
\text { entrance dissection }\end{array}$} & \multicolumn{3}{|c|}{$\begin{array}{c}\text { Parameters of } \\
\text { intrastromal rings }\end{array}$} \\
\hline & & & $\begin{array}{l}\text { Diameter } \\
(\mathrm{mm})\end{array}$ & Depth $(\mu m)$ & $\begin{array}{l}\text { Width } \\
(\mathrm{mm})\end{array}$ & $\begin{array}{l}\text { Length } \\
(\mathrm{mm})\end{array}$ & $\begin{array}{l}\text { Entry } \\
\text { angle }\left({ }^{\circ}\right)\end{array}$ & $\begin{array}{l}\text { Height } \\
(\mu \mathrm{m})\end{array}$ & $\begin{array}{l}\text { Width } \\
(\mathrm{mm})\end{array}$ & $\begin{array}{l}\text { Inner } \\
\text { diameter } \\
(\mathrm{mm})\end{array}$ \\
\hline I & Experimental group & 4 & & & \multicolumn{6}{|c|}{ Transparent, intact corneas } \\
\hline II & $\begin{array}{l}\text { Formation of the } \\
\text { intrastromal pocket } \\
\text { with its following } \\
\text { opening }\end{array}$ & 4 & 9.0 & $\begin{array}{l}80 \% \text { of minimal } \\
\text { pachymetry data, } \\
\text { measured along } \\
5.0 \mathrm{~mm} \text { periphery of } \\
\text { the optical zone }\end{array}$ & 1.0 & 4.0 & $30^{\circ}$ & - & - & - \\
\hline III & $\begin{array}{l}\text { Formation of the } \\
\text { intrastromal pocket } \\
+ \text { implantation of } \\
\text { an intrastromal ring } \\
\text { using the standard } \\
\text { technology }\end{array}$ & 4 & 9.0 & $\begin{array}{l}62-72 \% \text { of minimal } \\
\text { pachymetry data, } \\
\text { measured along } \\
5.0 \mathrm{~mm} \text { periphery } \\
\text { of the optical zone }\end{array}$ & 1.0 & 4.0 & $30^{\circ}$ & 250 & 0.5 & 5.0 \\
\hline IV & $\begin{array}{l}\text { Formation of the } \\
\text { intrastromal pocket } \\
+ \text { implantation of } \\
\text { an intrastromal ring } \\
\text { using the optimized } \\
\text { technology }\end{array}$ & 4 & 8.0 & $\begin{array}{l}80 \% \text { of minimal } \\
\text { pachymetry data, } \\
\text { measured along } \\
5.0 \mathrm{~mm} \text { periphery } \\
\text { of the optical zone }\end{array}$ & 1.0 & 4.0 & $30^{\circ}$ & 250 & 0.5 & 5.0 \\
\hline
\end{tabular}

research. The rabbits' keeping and use corresponded to the rules accepted by the institute, the National Research Council recommendations, and the national law. The study involved 16 eyes ( 8 rabbits) which were divided into four groups with four eyes in each depending on the operation methods (Table 1). In all groups except group I the operations were performed under general (intramuscular injection of $5 \%$ ketamine) and local (instillation of $0.3 \%$ inokain) anesthesia. The intrastromal pocket's formation was performed using the FL FSL IntraLase FS $60 \mathrm{kHz}$ (AMO, USA) with the pulse energy $1.7 \mu \mathrm{J}$, the distance between pulses was $4 \mu \mathrm{m}$, and the distance between the levels was $4 \mu \mathrm{m}$ (Fig. 1). The domestic analogs of the MyoRing - the experimental intrastromal rings of

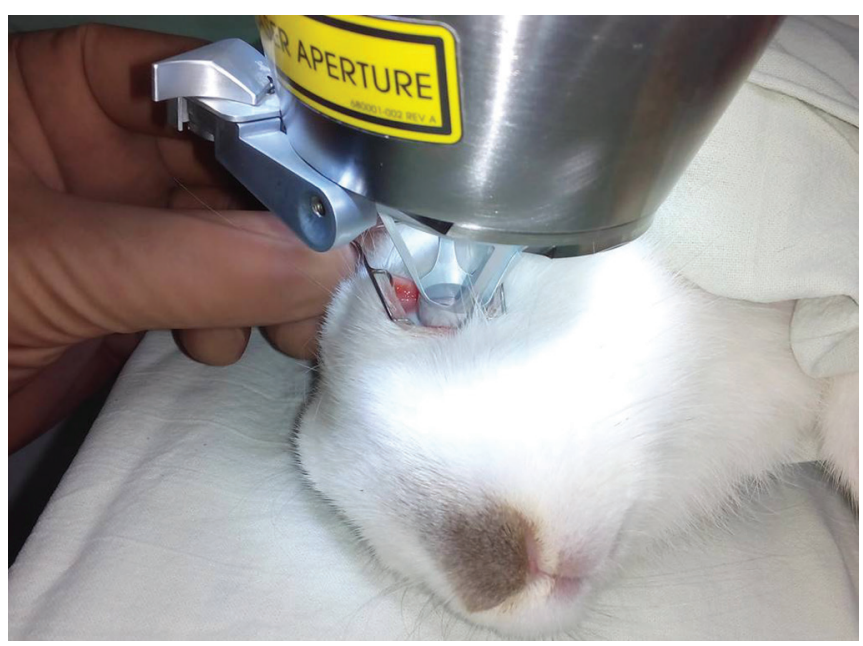

Fig. 1: Formation of an intrastromal pocket using the FL IntraLase FS $60 \mathrm{kHz}$ polymethylmethacrylate (made by “Reper-NN," Russia) were implanted into the eyes of groups III and IV (Fig. 2). In group III, the intrastromal pocket's depth was 62 to $72 \%$ of the minimal pachymetry data measured along $5.0 \mathrm{~mm}$ periphery of the optical zone in order to place the intrastromal rings at the same depth in the anterior part of the posterior corneal stroma in accordance with the standard technology of the MyoRing implantation $(300 \mu \mathrm{m})$ as recommended by Daxer to apply in clinical use.

In group IV, the intrastromal pocket was formed at the depth of $80 \%$ of the minimal pachymetry data measured along $5.0 \mathrm{~mm}$ periphery of the optical zone in accordance with the optimized technology of the MyoRing implantation. The pachymetry at five points (in the center and at

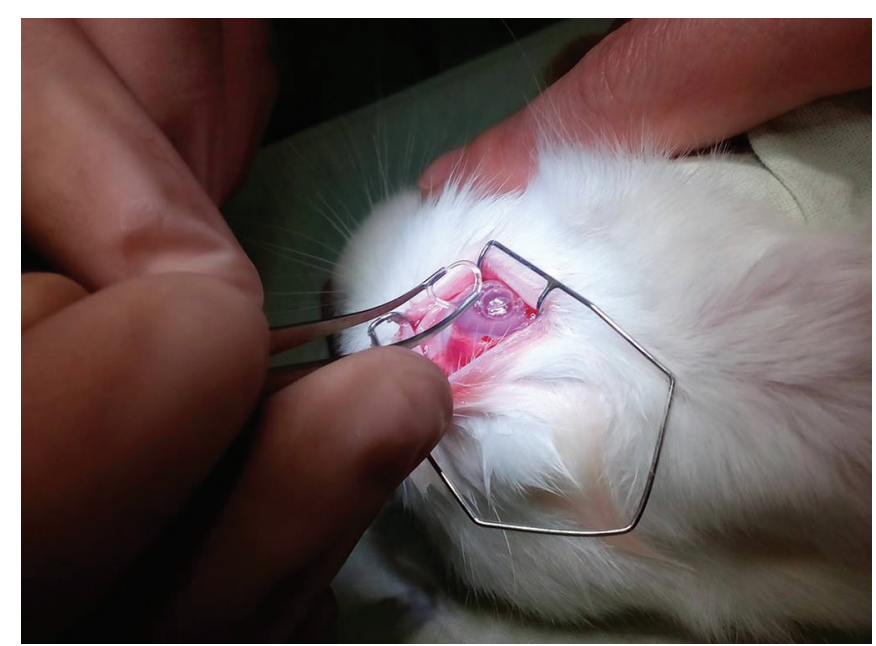

Fig. 2: Implantation of an intrastromal ring 
four points placed along $5 \mathrm{~mm}$ periphery of the optical zone) was done in all eyes before operation. In all eyes the mean corneal thickness in the center was $347 \pm 5 \mu \mathrm{m}$ (from 342 to $356 \mu \mathrm{m}$ ), along the periphery of the optical zone it was $368 \pm 7 \mu \mathrm{m}$ (from 359 to $375 \mu \mathrm{m}$ ). Thus, the groups were comparable on the grounds of the corneal thickness, and the difference of the corneal thickness in the center $(\mathrm{p}=0.6542)$ and in $5.0 \mathrm{~mm}$ optical zone ( $p=0.5485$ ) was not more than $4.2 \%$ between the groups.

One month after the operation, the rabbits' slaughter was performed by air embolism in the pulmonary artery, and the eye bulbs enucleation was done.

To research the biomechanic properties of rabbits' corneas, the corneoscleral stripes $11 \times 20 \mathrm{~mm}$ (Fig. 3) were cut out and fastened on the peripheral rims between the claws of the universal testing machine IR 5082-5 (Fig. 4) at a distance of $11 \mathrm{~mm}$ from each other so that only the studied cornea was placed between claws' edges. We studied the capability of the rabbits' corneas to stretch out under the growing stress with Young's modulus (modulus of elasticity) calculation, and the dependence of stress applied to the test sample from its rate of strain. The tension was linearly increasing at a speed of $50 \mathrm{~mm}$ per minute. Young's modulus was calculated using the formula $E=(F \cdot 1) /(\Delta l \cdot S)$, where $E$ is Young's modulus $(\mathrm{mPa}) ; \mathrm{F}$ is stress on the straight line segment of a sample $(\mathrm{N}) ; 1$ is the initial length of a sample $(\mathrm{mm})$;

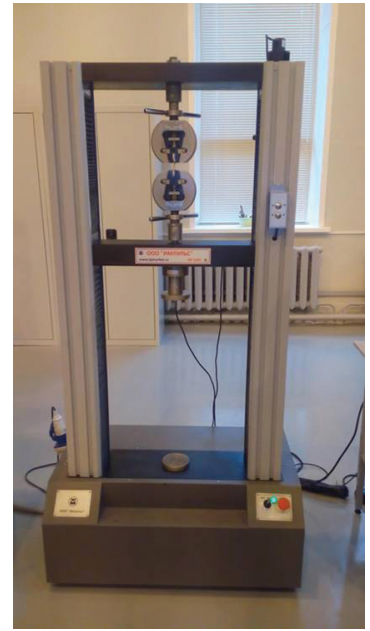

Fig. 3: Universal testing machine, IR 5082-5

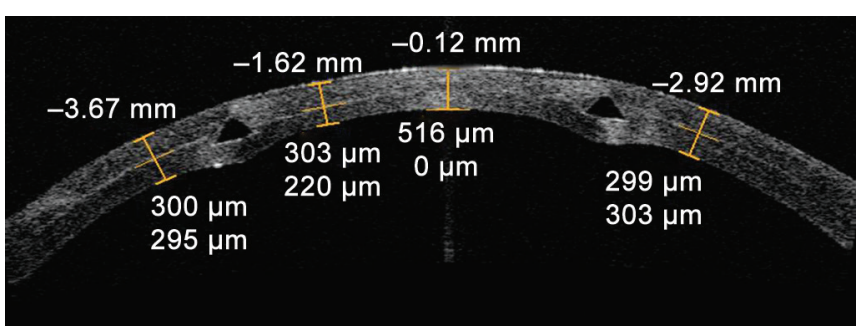

Fig. 4: Optical coherence tomography of the cornea the day after the MyoRing implantation using the standard technology
$\Delta \mathrm{l}$ is the deformation increment on the linear segment of a sample (mm); and $S$ is the initial cross-sectional area of a sample $\left(\mathrm{mm}^{2}\right)$.

In the clinical part of the research, the surgical treatment results of 70 patients (76 eyes) with $\mathrm{KC}$ at stages II and III were analyzed according to Amsler's classification (1961). ${ }^{6}$ All patients were divided into two groups according to the operation technology. In group I, the patients with KC underwent the MyoRing implantation using the standard technology following Daxer's recommendations. The patients of group II underwent the MyoRing implantation using the optimized technology. According to KC stage, all patients were divided into two subgroups. In subgroup I, there were patients with KC at stage II, in subgroup II there were patients with KC at stage III (Table 2). All patients underwent the MyoRing implantation into an intrastromal pocket formed with FL IntraLase FS 60 $\mathrm{kHz}(\mathrm{AMO})$. The parameters of intrastromal rings of all patients were calculated by Daxer's nomogram $(2008)^{2}$ which takes into account the mean value of keratometry and the minimal thickness of cornea.

Before and after operation, all the patients underwent visometry, biomicroscopy, keratotopography, the analyses of biomechanical properties of the cornea in ocular response analyzer (Reichert, USA), the analyses of anterior and posterior corneal surfaces' elevation according to Pentacam data (Oculus, Germany), and minimal corneal pachymetry including the cornea area above the MyoRing according to the optical coherent tomography (OCT) data provided by OCT RTV 100-CAM (Optovue, Inc., СШA). The visometric parameters [uncorrected visual acuity (UCVA) and corrected visual acuity (CVA)] were estimated according to LogMAR eye chart. The mean follow-up period was 38 months (12-42 months).

The statistical analysis of the experiment outcomes was carried out on a personal computer with the statistical software Statistica 6.1 (StatSoft, USA). The single-factor analysis of variance (ANOVA) was performed among four comparison groups in the experimental part of the research to determine the significant difference of mean values of the stress-strain curve and the Young's modulus, and in the clinical part of the research to determine the significant difference between the clinical and functional parameters in different follow-up periods. In the experimental part of the research, during the postoperative period the estimation of significance of the differences between the independent comparative parameters (the stress-strain curve and the Young's modulus) was made by the parametric criterion $t$ for independent variables. In the clinical part of the research, the statistical analyses of each preoperative parameter between both comparative subgroups was done by the parametric criterion $t$ for independent variables, and within each subgroup 


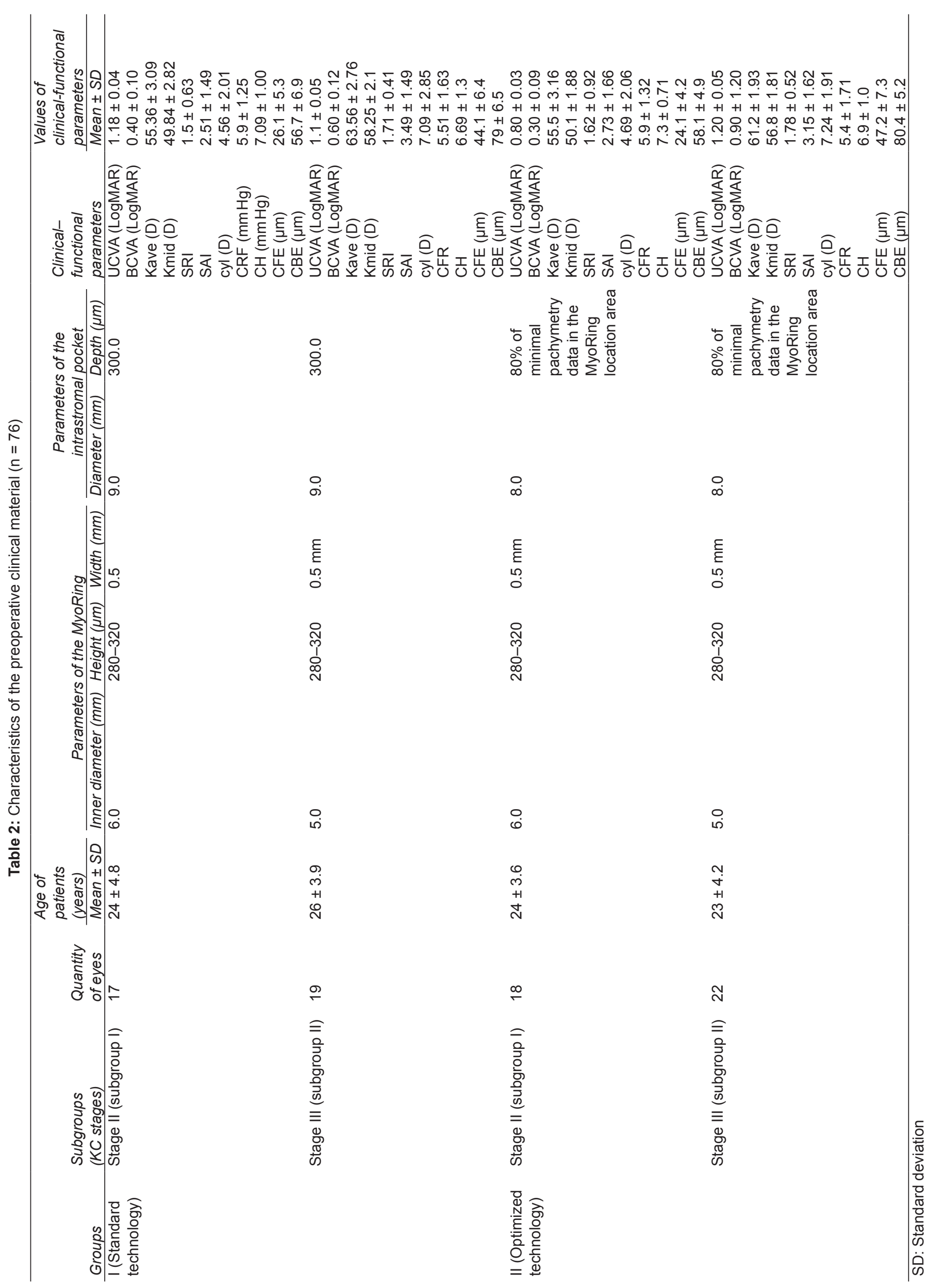


the significance of differences of the studied parameters $1,6,12,24$, and 38 months after operation was estimated in comparison with the preoperative parameters by parametric criterion $t$ for dependent variables due to the symmetrical distribution of all values. The differences of studied parameters were considered to be significant at $\mathrm{p}<0.05$.

\section{RESULTS}

When we increased the relative cornea deformation by $7 \%$ during the experimental part of the research, we observed a difference in the run of the stress-strain curves which depended on the applied strain for cornea stretching ( $p=0.0125$, ANOVA; Fig. 5). Less strain was required to stretch rabbit cornea samples in group II in comparison with group I ( $p=0.0055)$. The strain value of groups III and IV samples after the rings implantation into the intrastromal pocket was higher than that of group I, the highest strain value was in group IV samples $(p=0.0186$, ANOVA). The strain and thinning of the corneal samples were observed outside the implanted intrastromal rings. The Young's modulus demonstrating the cornea's ability to change its form and size under the strain was calculated in all groups. The Young's modulus values were affirmed by the strain distribution in the examined groups ( $p=0.0015$; Fig. 6).

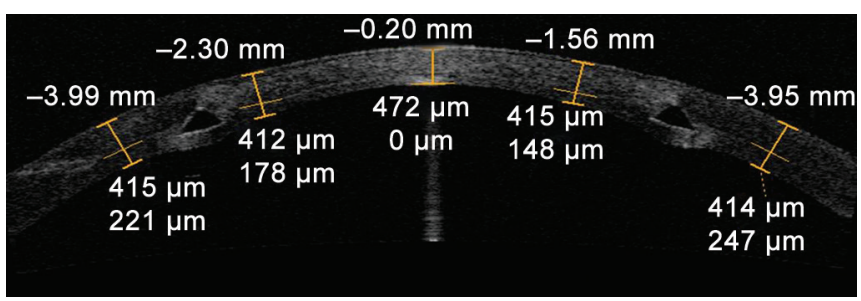

Fig. 5: Optical coherence tomography of the cornea the day after the MyoRing implantation using the optimized technology

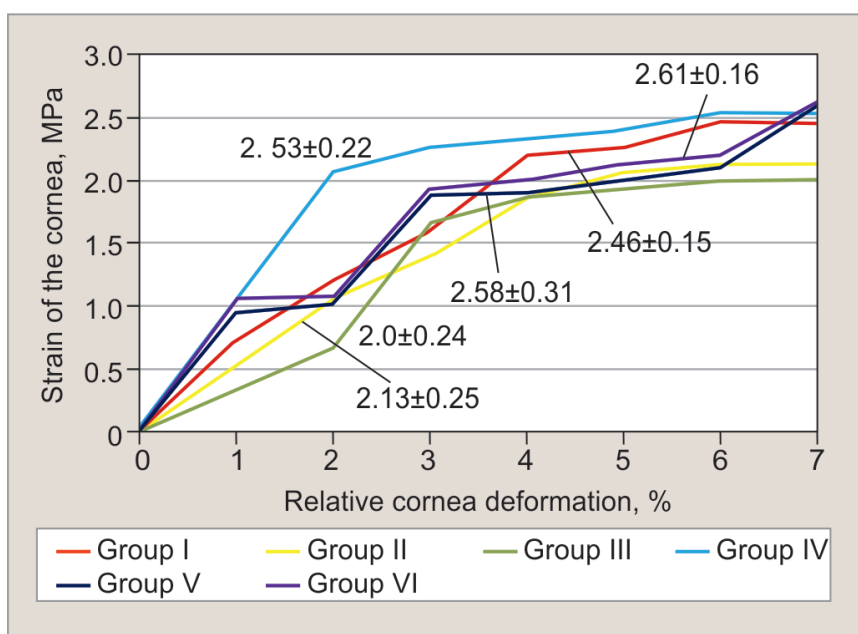

Graph 1: Schedule of the stress-strain curve
In both groups, we observed no intraoperative complications in the clinical part of the research. The early postoperative periods passed areactively. On the first postoperative days, all patients had quiet eyes. The optical media were biomicroscopically transparent, in eyes of some patients we visualized local subconjunctival hemorrhages as a result of a vacuum ring application, the MyoRing were in the intrastromal pockets at the calculated depth, and the OCT data confirmed it (Graphs 1 and 2).

Before operation we found out a significant difference between the first subgroups of both groups in the following parameters: UCVA $(\mathrm{p}<0.01)$, cylindrical refraction component according to keratotopograms (cyl; $\mathrm{p}<0.001)$, corneal resistance factor $(\mathrm{CRF} ; \mathrm{p}<0.05)$, corneal hysteresis $(\mathrm{CH}$; $\mathrm{p}<0.05)$. In subgroup II, significant difference was found in best corrected visual acuity (BCVA; $p<0.001)$, CRF $(p<0.05)$, and CH $(p<0.05)$.

The next day after operation, the mean minimal corneal thickness above the MyoRing was $300 \pm 4.0 \mu \mathrm{m}$

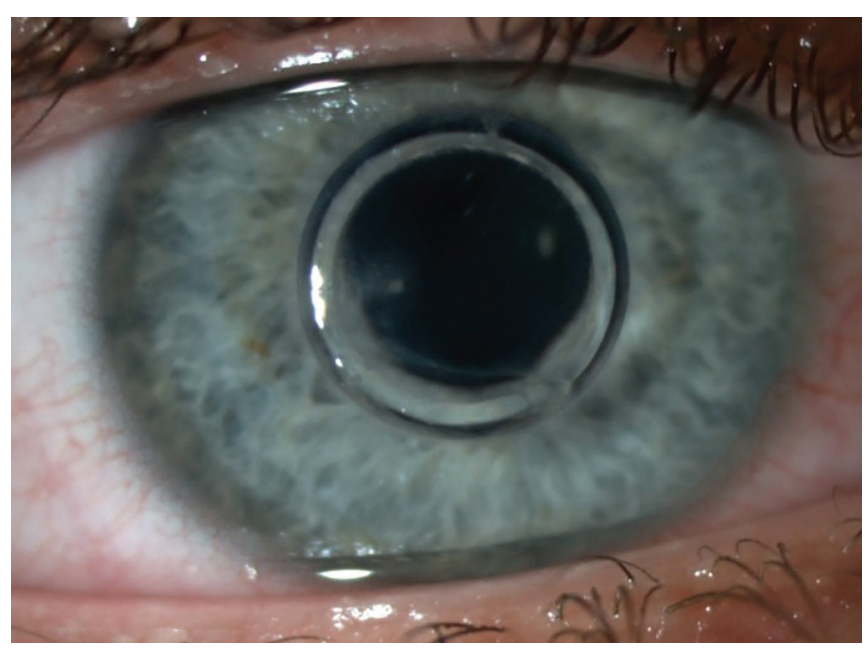

Fig. 6: Protrusion of the MyoRing 24 months after the operation performed with the standard technology

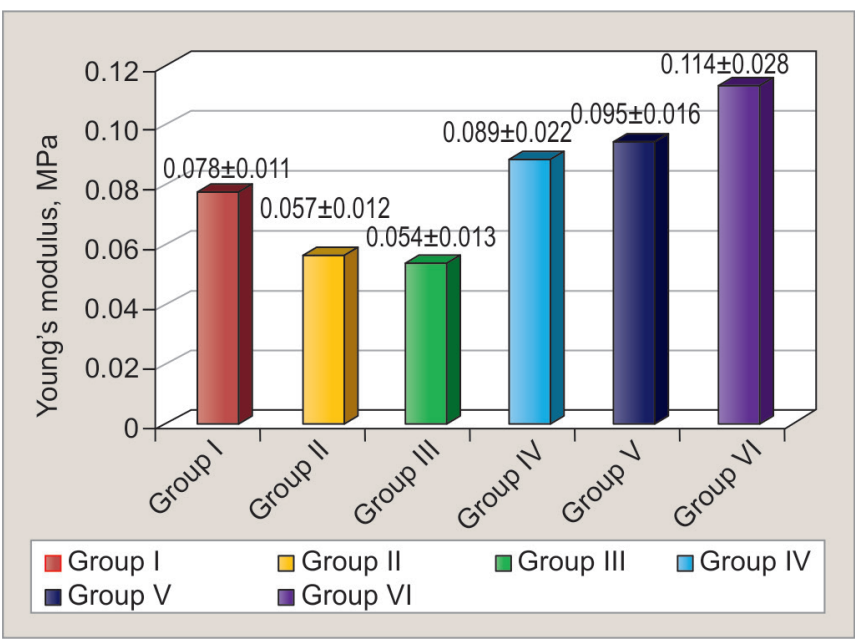

Graph 2: Histogram of the Young's modulus distribution in the experimental groups 
Table 3: Dynamics of the pachymetry data changes after the implantation of the intrastromal MyoRing using the standard (group I, $\mathrm{n}=36$ ) and the optimized (group II, $\mathrm{n}=40$ ) technologies with the FL in patients with keratoconus at stages II and III (mean \pm SD)

\begin{tabular}{|c|c|c|c|c|c|c|c|c|}
\hline \multirow[b]{2}{*}{ Groups } & \multirow[b]{2}{*}{ Parameters } & \multirow{2}{*}{$\begin{array}{c}\begin{array}{c}\text { Before } \\
\text { operation }\end{array} \\
\text { Mean } \pm S D\end{array}$} & \multicolumn{2}{|c|}{$\begin{array}{c}6 \text { months after } \\
\text { operation }\end{array}$} & \multicolumn{2}{|c|}{$\begin{array}{c}12 \text { months after } \\
\text { operation }\end{array}$} & \multicolumn{2}{|c|}{$\begin{array}{c}38 \text { months after } \\
\text { operation }\end{array}$} \\
\hline & & & Mean $\pm S D$ & $p$-value & Mean $\pm S D$ & $p$-value & Mean $\pm S D$ & $p$-value \\
\hline \multirow[t]{2}{*}{1} & Minimal corneal pachymetry $(\mu \mathrm{m})$ & $432 \pm 36.7$ & $434 \pm 34.7$ & 0.0263 & $433.0 \pm 32.9$ & 0.0133 & $431.1 \pm 34.2$ & 0.0128 \\
\hline & $\begin{array}{l}\text { Corneal thickness above the } \\
\text { MyoRing }(\mu \mathrm{m})\end{array}$ & - & $147.2 \pm 27.0$ & 0.0389 & $130.9 \pm 22.8$ & 0.0125 & $126.1 \pm 20.4$ & 0.0022 \\
\hline \multirow[t]{2}{*}{ II } & Minimal corneal pachymetry $(\mu \mathrm{m})$ & $452.1 \pm 33.5$ & $453.2 \pm 29.7$ & 0.0421 & $452.0 \pm 26.5$ & 0.0368 & $453.2 \pm 24.4$ & 0.0155 \\
\hline & $\begin{array}{l}\text { Corneal thickness above the } \\
\text { MyoRing }(\mu \mathrm{m})\end{array}$ & - & $228.8 \pm 26.6$ & 0.0394 & $227.9 \pm 25.4$ & 0.0269 & $227.5 \pm 23.1$ & 0.0028 \\
\hline
\end{tabular}

SD: Standard deviation

in group I and $377.9 \pm 30.1 \mu \mathrm{m}$ in group II. Within 6 months of the follow-up period in both subgroups of group I, we observed the applanation of corneal surface with its top centering that led to the statistically significant decrease of Kave, Kmax, cyl, cornea's front elevation (CFE) and cornea's back elevation (CBE; $\mathrm{p}<0.01$, ANOVA), surface asymmetry index (SRI), surface regularity index (SAI) indices $(p<0.01$, ANOVA), the visometric data increase (UCVA and BCVA; $p<0.001$, ANOVA), and the increase of biomechanic corneal properties $(\mathrm{CRF}, \mathrm{CH}$; $\mathrm{p}<0.001$, ANOVA), but the minimal corneal thickness above the MyoRing was stable $(\mathrm{p}=0.6245$, ANOVA; Table 3).

Within the period from 6 to 38 months of follow-up, we marked a gradual decline of the minimal corneal thickness above the MyoRing ( $\mathrm{p}<0.01$, ANOVA; Table 4) which was accompanied by corneal curvature regress (increase of Kave, Kmax, cyl; $\mathrm{p}<0.01$, ANOVA) and CBE ( $p<0.01$, ANOVA). Thereat reached by the 12th month of the follow-up period. UCVA and BCVA parameters and SRI, SAI, CRF, CH, CFE indices were stable throughout the follow-up period ( $p>0.05$, ANOVA). In both subgroups of group II, we observed the gradual improvement of all clinical-functional parameters up to the 12th month after operation $(\mathrm{p}<0.01, \mathrm{ANOVA})$, and then the aforementioned parameters were found stable throughout the remaining follow-up period ( $p>0.05$, ANOVA). Within the period from 6 to 38 months of follow-up, the minimal corneal thickness above the MyoRing remained stable ( $p>0.05$, ANOVA). In both groups, the minimal corneal thickness remained stable throughout 38 months of the follow-up period ( $p>0.05$, ANOVA).

In group II, a bigger increase in the biomechanical properties of the cornea was observed in comparison with group I. Thus, 38 months after operation in group II, subgroup I (with KC at stage II) we registered a bigger increase of CRF by $0.63 \pm 0.18 \mathrm{~mm} \mathrm{Hg}(\mathrm{p}=0.0164)$, and in $\mathrm{CH}$ by $0.89 \pm 0.33 \mathrm{~mm} \mathrm{Hg}(\mathrm{p}=0.0185)$ in comparison with group I, subgroup I. In group II, subgroup II (with KC at stage III), we registered a bigger increase in CRF by $0.3 \pm$
$0.06 \mathrm{~mm} \mathrm{Hg}(\mathrm{p}=0.0089)$ and in $\mathrm{CH}$ by $0.23 \pm 0.09 \mathrm{~mm} \mathrm{Hg}$ $(p=0.0054)$ in comparison with group I, subgroup II.

In group II within 6 months after operation using the optimized technology of formation of the intrastromal pocket with a diameter $8.0 \mathrm{~mm}$, we observed a smaller decrease of Kave and Kmax by 0.5 to $0.75 \mathrm{D}$ in patients of subgroup I (with KC at stage II; $\mathrm{p}=0.0085$ ) and by 1.0 to $1.25 \mathrm{D}$ in patients of subgroup II (with KC at stage III; $\mathrm{p}=0.0078)$ in comparison with the standard technology.

In the late postoperative period ( 24 months after operation) in group I, subgroup II, there was one case of the MyoRing protrusion with a sharp visual acuity fall, increase of keratotopography parameters (Kave, Kmid, SRI, SAI, cyl), decrease of the biomechanic corneal properties $(\mathrm{CRF}, \mathrm{CH})$ and of pachymetry data (minimal cornea thickness, corneal thickness above the MyoRing; Fig. 7). This particular patient had such risk factors aggravating the disease as the progressive $\mathrm{KC}$ at stage III, young age (18 years), low biomechanical properties of the cornea ( $\mathrm{CRF}$ and $\mathrm{CH}<4.0 \mathrm{~mm} \mathrm{Hg}$ ), borderline value of the recommended minimal cornea thickness for the applied technology $(350 \mu \mathrm{m})$, low compliance with the doctor's requirements-the patient failed to comply with the doctor's requirements of dynamic postoperative examination during 2 years. The MyoRing was removed and the deep anterior lamellar keratoplasty was performed. There were no postoperative complications in group II.

\section{DISCUSSION}

Less strain rate was required for stretching the rabbits' cornea samples in group III in comparison with group I $(p=0.0185)$ due to formation of $9.0 \mathrm{~mm}$ intrastromal pocket, which reduces the biomechanical properties of the cornea. The strain value of samples in groups III and IV after the implantation of rings into intrastromal pockets was bigger than that in group I resulting from the corneal stretching resistance and shortening in its transverse size due to an additional frame creation by the ring $(\mathrm{p}=0.0125$, ANOVA). A deeper location of the ring in the posterior part of the stroma in group IV samples in comparison 
Comparative Analysis of the Intrastromal MyoRing Implantation

Table 4: Dynamics of the clinical-functional parameters changes after the implantation of the intrastromal MyoRing using the standard (group I, $n=36$ ) and the optimized (group II, $n=40$ ) technologies with the FL in patients with keratoconus at stages II and III (mean \pm SD)

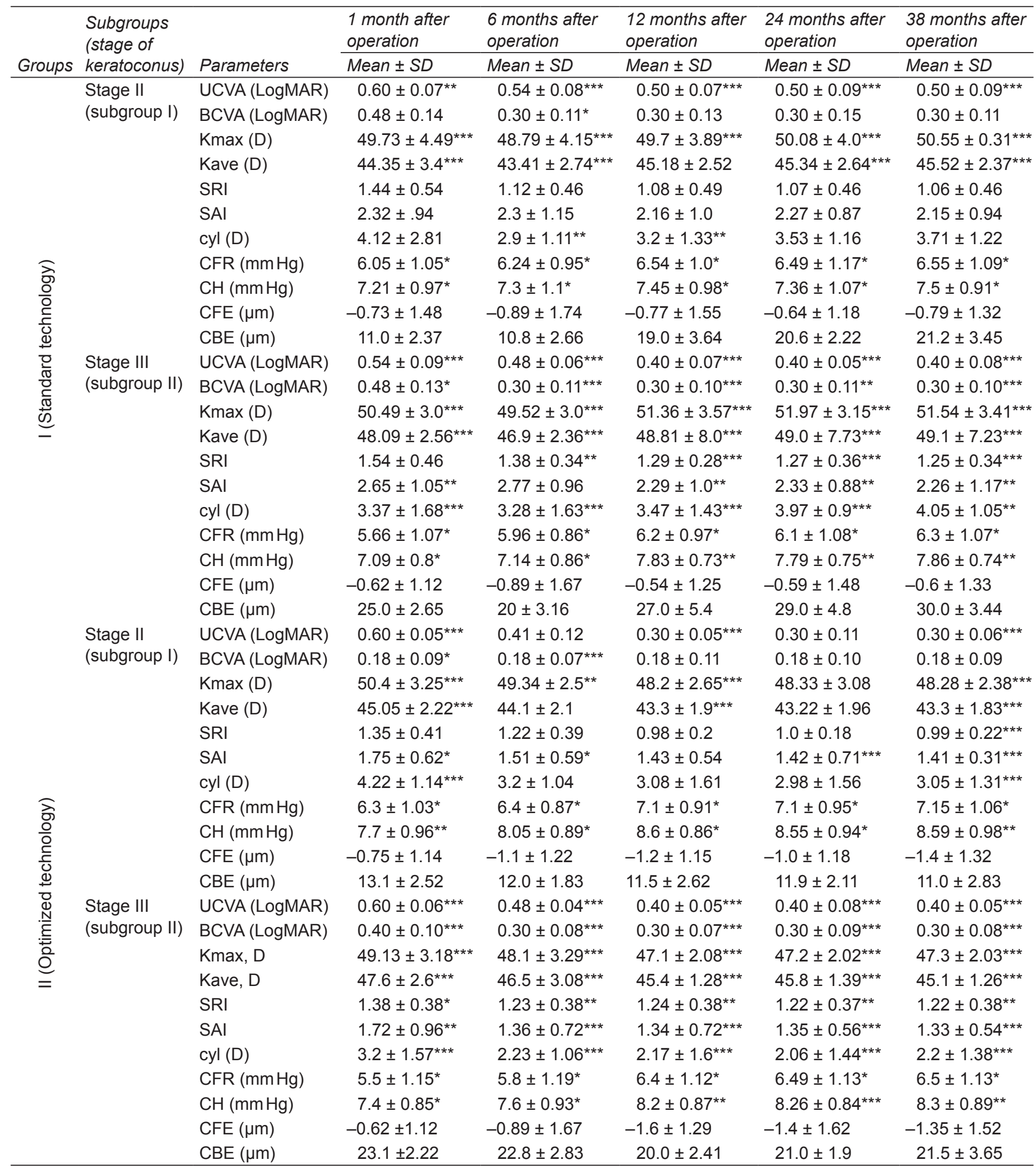

Significant difference between the parameters in each subgroup at different follow-up periods as compared with the preoperative data, where ${ }^{*} \mathrm{p}<0.05 ;{ }^{* *} \mathrm{p}<0.01 ;{ }^{* * *} \mathrm{p}<0.001$; SD: Standard deviation

with group III led to the increase of strain applied to the samples to stretch them $(\mathrm{p}=0.0044)$.

In both groups, 12 months after operation, we observed no reduction of the minimal cornea thickness according to the OCT data, it remained stable throughout the whole follow-up period ( $p>0.05$, ANOVA), which indicates the stabilization of the disease and coincides with Daxer's data. ${ }^{4}$ Absence of a decrease in the biomechanical parameters of the cornea ( $\mathrm{CRF}$ and $\mathrm{CH})$, keratotopography indices (SRI, SAI), CFE, and visometric 


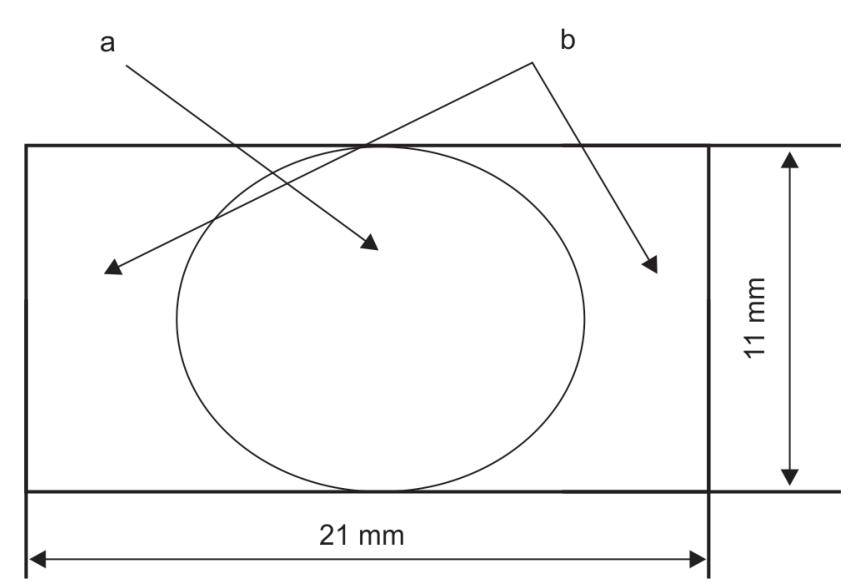

Figs 7A and B: Scheme of cutting-out the corneoscleral stripes for experiments, where (A) cornea; $(B)$ scleral parts, used for fastening the corneoscleral stripes between the claws of the tension testing machine

data (UCVA and BCVA) decrease also confirms the stabilization of the disease in both groups. In his technology of operation, Daxer recommends in all cases to form an intrastromal pocket with a diameter $9.0 \mathrm{~mm}$ using the Pocket Maker microkeratome at the depth of $300 \mu \mathrm{m}$ for which a special applanator is developed but it limits the surgeon in choosing the depth of the MyoRing placement. Due to the trapezoidal shape of the anterior surface of the ring and its flexibility on the contrary, and to the biomechanical corneal resistance on the contrary, the MyoRing after its implantation presses into the corneal stroma above it. Thus, in the follow-up period from 6 to 38 months we observed a gradual reduction of the minimal corneal thickness above the MyoRing ( $p<0.01$, ANOVA). Due to the decrease of the corneal thickness above the ring, the area without the frame support of the corneal ring extends, and it leads to the regress of the corneal curvature (increase of Kave, Kmax, cyl; $p<0.01$, ANOVA), and CBE level ( $p<0.01$, ANOVA) reached after the MyoRing implantation. Therefore, it is necessary to observe these patients during a longer period in order to find out the risk of a ring protrusion in the late postoperative period. In our practice, we observed one case of the ring protrusion 24 months after the implantation. The increase of the corneal curvature at 0.75 to $1.25 \mathrm{D}$ in all patients of group I for up to 38 months of the follow-up period ( $p<0.01)$ makes it necessary to amend the calculation of the MyoRing height considering the revealed insufficient correction. In group II, the application of the FL IntraLase FS $60 \mathrm{kHz}$ allows to form an intrastromal pocket at any depth, including the depth of $80 \%$ of the minimum cornea thickness at the area of the MyoRing location taking into account a high cutting accuracy (tolerance no more than 6-8 $\mu \mathrm{m}) .{ }^{9}$ Thus, an intrastromal pocket is formed deeper in the posterior stroma as compared with the standard technology, and the individual corneal thickness is taken into account in each case and this reduces the biomechanical stability of the stroma and thereby reduces the risk of the MyoRing protrusion. In group II, the location of the intrastromal pocket at a depth of $80 \%$ of the minimal corneal thickness in the MyoRing location area has led to the disease stabilization. Within the period from 12 to 38 months after operation, no growth of corneal curvature and CBE was observed ( $p>0.05$, ANOVA). The corneal thickness above the ring remained stable during the follow-up period from 6 to 38 months ( $p>0.05$, ANOVA). Thus, there has been created a frame for a bigger cornea area as compared with the standard technology. This may suggest a lower risk of the MyoRing protrusion in the follow-up period of more than 38 months, and the optimized technology of the MyoRing implantation can be recommended as a technology of choice. In patients of group II with KC at stage II $(\mathrm{p}<0.05)$ and at stage III $(p<0.01)$, a higher biomechanical stability of the cornea may be connected both with the increase of the MyoRing location depth and with the decrease of the dissection area in the cornea while forming an intrastromal pocket of a smaller diameter in comparison with the standard technology. The application of the optimized technology of implantation of the MyoRing with an internal diameter $5.0 \mathrm{~mm}$ into an intrastromal pocket with a diameter $8.0 \mathrm{~mm}$ leads to smaller decrease of Kave and Kmax at 1.0 to $1.25 \mathrm{D}(\mathrm{p}<0.01)$, and the use of the ring with an internal diameter $6.0 \mathrm{~mm}$ leads to the decrease of Kave and Kmax at 0.5 to $0.75(\mathrm{p}<0.01)$ as compared with the standard technology, which is a necessary consideration while calculating the height of the MyoRing.

\section{CONCLUSION}

Thus, the comparative analysis of the intrastromal MyoRing implantation using the FL by standard and optimized technologies in the experiment and based on the long-term clinical and functional results in patients with KC at stages II and III showed at the follow-up period of 38 months the following:

- The intrastromal ring implantation leads to the increase of the cornea's strength characteristics, which are more uttered after implantation of an intrastromal ring in the pocket at the depth of $80 \%$ from the minimum pachymetry data in the ring location area in comparison with the depth of 62 to $72 \%$ (which corresponds to the depth of $300 \mu \mathrm{m}$ using the standard technology).

- Stabilization of the disease in both groups was confirmed by the absence of the minimum corneal thickness reduction and decrease of the biomechanical parameters of the cornea, keratotopography parameters, and visometric data;

- The application of the optimized technology of the MyoRing implantation in comparison with the 
standard technology allows to improve significantly the corneal biomechanical parameters $(\mathrm{CRF}, \mathrm{CH})$ and reduce the risk of the ring protrusion.

- Using the optimized technology, it is necessary to amend the calculation of the MyoRing height taking into account the MyoRing diameter and the diameter of the intrastromal pocket.

- Using the standard technology when calculating the height of the ring, it is necessary to amend the nomogram proposed by Daxer taking into account the insufficient correction at 0.75 to $1.25 \mathrm{D}$ in the late postoperative period.

- There is a need for further postoperative follow-up to register the remote clinical and functional results of the two experimental groups in the later postoperative period.

\section{REFERENCES}

1. Daxer A. Adjustable intracorneal ring in a lamellar pocket for keratoconus. J Refract Surg 2010 Mar;26(3):217-221.

2. Daxer A, Mahmood H, Venkateswaran RS. Intracorneal continuous ring implantation for keratoconus: one year follow-up. J Cataract Refract Surg 2010 Aug;36(8):1296-1302.

3. Daxer A. MyoRing for central and noncentral keratoconus. Int J Kerat Ect Cor Dis 2012 May-Aug;1(2):117-119.

4. Daxer A. Corneal thickness after MyoRing implantation for keratoconus. Int J Kerat Ect Cor Dis 2014 Jan-Apr;3(1):15-19.

5. Daxer B, Mahmood H, Daxer A. MyoRing treatment for keratoconus: DIOPTEX PocketMaker vs. Ziemer LDV for corneal pocket creation. Int J Kerat Ect Cor Dis 2012 Sep-Dec;1(3): 151-152.

6. Janani L, JadidiK, MosaviSA, NejatF, Naderi M,NourijelyaniK. MyoRing implantation in keratoconic patients: 3 years follow-up data. J Ophthalmic Vis Res 2016 Jan-Mar;11(1): 26-31. 